\title{
Obesity and chronic disease: always offender or often just accomplice?
}

\author{
Garry Egger ${ }^{1,2 *}$ and John Dixon ${ }^{3}$ \\ ${ }^{1}$ School of Health and Applied Sciences, Southern Cross University, Lismore, NSW, Australia \\ ${ }^{2}$ Centre for Health Promotion and Research, PO Box 313, Fairlight, Sydney, NSW, Australia \\ ${ }^{3}$ Obesity Research Unit, Department of Primary Health Care, Monash University, Melbourne, Australia
}

(Received 23 September 2008 - Revised 27 January 2009 - Accepted 8 April 2009 - First published online 18 May 2009)

Over a decade ago, the finding of a form of low-grade systemic inflammation ('metaflammation') associated with obesity, insulin resistance and chronic disease proffered a causal explanation for the latter. However, recent work has shown that metaflammation is also associated with several modern lifestyle-related and environmental inducers, with or without obesity. Here, we present accumulating data to show a link between metaflammation and a number of non-microbial environmental and lifestyle stimulants, both with and without obesity. This implies that obesity may often be an accomplice to, as much as an offender in, major metabolic disease. The real (albeit distal) cause of such a disease appears to lie in aspects of the modern techno-industrial environment driving unhealthy lifestyle behaviours. If true, this suggests that while individual weight loss may be a component of chronic disease management, it may be neither 'necessary' nor 'sufficient' to reduce the problem at a population level. Greater multidisciplinary and policy input is needed to modify the economic and political drivers of the modern, obesogenic environment.

Obesity: Inflammation: Environment: Lifestyle

Obesity is known to be a cause of chronic disease, although the exact mechanisms for this are unclear. Over a decade ago ${ }^{(1)}$, the discovery of a form of subclinical, low-grade systemic inflammation, later called 'metaflammation' (2) (referring to metabolically triggered inflammation) associated with both obesity and chronic disease, raised hopes of an improved understanding of the causal links between the two, as this form of inflammation is linked with insulin resistance and chronic disease, and obesity seemed to be the driving cause ${ }^{(2)}$. However, increasing knowledge about metaflammation, and its connection with a range of lifestyle-related and environmental factors (diet, inactivity, smoking, sleep, stress, pollution, etc), in the absence, as well as in the presence of obesity, suggests an alternative view; that is, obesity may often be just an accomplice to, as much as a perpetrator of, many metabolic diseases. The real (albeit distal) determinants of such diseases appear to lie in aspects of the modern techno-industrial environment enabling and encouraging such lifestyle-related immune stimuli, with an outcome potential in chronic diseases ranging from metabolic disorders $^{(3)}$ to certain forms of cancer $^{(4)}$. If this is the case, weight loss, while being a useful component of chronic disease management at the clinical level, may not always be either 'necessary' or 'sufficient', thus changing the nature of any proposed intervention to manage, at the population level, what should be seen as a natural physiological response to an unnatural, obesogenic ${ }^{(5)}$ environment.

\section{Inflammation and 'metaflammation'}

Classical inflammation represents an acute immune reaction to infection or injury. Metaflammation ${ }^{(2)}$ differs from this in that: (a) it does not involve the classical symptoms of inflammation (tumour, rubor, dolour and calor); (b) it causes only a small rise in immune system markers (i.e. 4-6-fold $v$. several 100-fold); (c) it results in chronic, rather than acute, allostasis; (d) it has its effects systemically; (e) its antigens are less apparent as foreign agents or microbial organisms (and hence may be better referred to as 'inducers $\left.{ }^{(6)}\right)$; (f) it appears to perpetuate, rather than resolve, a disease ${ }^{(1-4,6)}$. Fig. 1 is a proposed graphical representation of the differences between the two forms of an inflammation.

There may be a number of agents associated with inducers of the metaflammatory response (shown on the right-hand side of Fig. 1), oxidised LDL being a known example. As well as aiding the atherogenic process, the leakage of foam cells from the phagocytosis of oxidised LDL formed in the arterial intima, through unstable plaques into the bloodstream, can have a thrombotic impact ${ }^{(3)}$. What is unclear to date, however, is the type and range of initial inducers of this and other processes stimulating metaflammation.

\section{Metaflammatory inducers}

Obesity is a cause of oxidative stress and insulin resistance ${ }^{(3)}$ and hence has been proposed as the primary causative factor in chronic and metabolic diseases such as type 2 diabetes $^{(7)}$. However, depending largely on the site of fat storage, obesity can be relatively benign, with little negative impact on health $^{(8)}$, or metabolic, with apparent links to a range of metabolic and other disorders ${ }^{(9)}$. Also, a significant proportion of obese individuals suffer none of the dysmetabolism expected from obesity, and a significant proportion of lean 


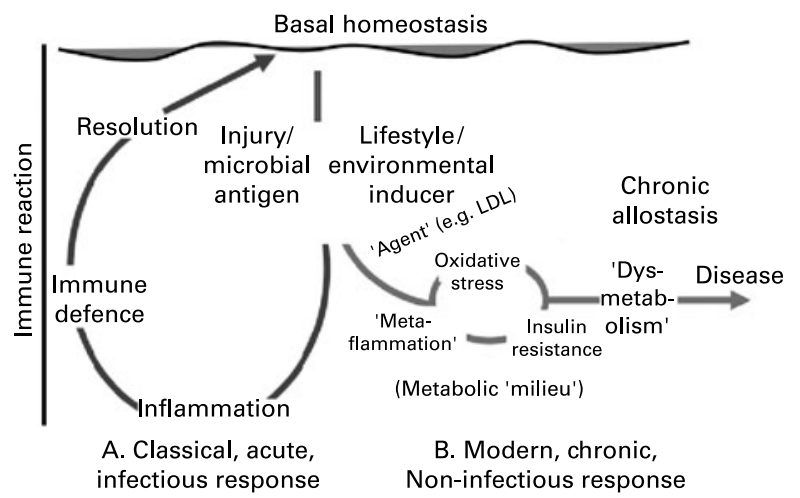

Fig. 1. A graphical representation of the difference between classical inflammation initiated by a microbial antigen or injury and metaflammation caused by lifestyle or environmental inducers. The order and other possible actions in the metabolic 'milieu' associated with metaflammation on the right-hand side of the graph are suggestive rather than definitive, but imply the mix of dysmetabolic actions associated with metaflammation. The scale of difference of immune reaction between the two forms (i.e. approximately 100-fold) is not implied. LDL, LDL-cholesterol.

individuals do ${ }^{(10,11)}$, suggesting a complicated association between obesity and disease.

There is a known link between obesity and metaflammation $^{(1,3)}$, but the causal relationship is not clear. Metaflammation is also associated with lifestyle and environmental factors that in some instances, but not always, cause obesity ${ }^{(12)}$. Awareness of the relationship between postprandial glucose and fat excursions and inflammatory markers ${ }^{(13)}$, and inflammatory responses to a range of other stimuli ${ }^{(14)}$, has enabled researchers to identify a number of inducers of inflammation (both pro- and anti-) in the body. A list of those with supporting evidence is shown in Table 1.

The left-hand side of Table 1 lists inducers with evidence of a pro-inflammatory (metaflammatory) response. As well as obesity and weight gain, this includes excessive alcohol ${ }^{(15)}$, acute excess energy intake ${ }^{(16)}$, a Western-style diet ${ }^{(17)}$ and a range of nutritive factors including saturated ${ }^{(18)}$ and transfats ${ }^{(19)}$, and excessive fructose- ${ }^{(20)}$ and glucose-rich foods ${ }^{(21)}$. Non-nutritive factors include inadequate sleep ${ }^{(22)}$, smoking $^{(23)}$, stress and depression ${ }^{(24)}$. While some of these (e.g. inactivity, excess energy intake) can cause weight gain, this is not a prerequisite for metaflammation to occur. Nutrient overload from acute excessive energy intake, for example, even in the absence of weight gain ${ }^{(25)}$, can abnormally tax the intracellular metabolism, cause acute oxidative stress, possibly disrupt normal protein folding in the endoplasmic reticulum $^{(6)}$ and lead to the accumulation of intracellular metabolites, activating inflammatory pathways and inducing insulin resistance ${ }^{(26)}$. Similarly, a high glycaemic index load, or even an excess of otherwise benign low glycaemic index foods, can have an inflammatory effect in the absence of obesity ${ }^{(27)}$. At the other extreme, a similar response results from extended fasting ${ }^{(28)}$ (probably because of the protective effects of insulin resistance in reducing energy losses). Paradoxically, there are also similar pro-inflammatory effects of both inactivity $^{(29)}$ and excessive exercise ${ }^{(30)}$, suggesting a healthy range of certain lifestyle actions, above or below which there is a negative metabolic outcome.

Fig. 2, which has been expanded from a previous article discussing lifestyle-related determinants of inflammation in adolescence $^{(31)}$, distinguishes between those factors with an aetiological effect on inflammation through obesity, and those with an effect 'independent' of it.

Obesity, while often present, may thus not be a necessary condition for metaflammation, or the chronic diseases associated with this. Many of the causes of obesity, on the other hand, as well as other non-obesogenic lifestyle-related inducers, seem to be more directly related aetiologically to chronic disease outcomes through the development of metaflammation. We have discussed this in more detail elsewhere ${ }^{(12)}$, pointing out that while the metaflammatory process appears to be a persistent causal factor, the association of inflammation with oxidative stress and insulin resistance in metabolic breakdown (described in Fig. 1 as the metabolic 'milieu') is not always clear.

\section{Anti-inflammatory inducers}

The pro-inflammatory inducers shown in Table 1 provide some suggestion of a distal causality, as all of these are relatively new to the human environment. This is supported by the identification of the inducers with evidence of an anti-inflammatory effect listed on the right-hand side of Table 1. Antiinflammatory responses (or neutral responses to corrections of those conditions causing a pro-inflammatory reaction on the left-hand side of Table 1 such as obesity and smoking)

Table 1. Lifestyle-related inducers with evidence for a pro- (metaflammatory) or anti-inflammatory response in human subjects*

\begin{tabular}{ll}
\hline & Metaflammatory inducers \\
\hline Pro-inflammatory & Anti-inflammatory/neutral \\
\hline Exercise (excessive) & Exercise/physical activity/CV fitness \\
& Walking/yoga/resistance, etc \\
& Extensive lifestyle change \\
Inactivity/low CV fitness & Nutrition \\
Nutrition & Alcohol (moderate) \\
Acute nutrient overload & Cocoa/dark chocolate \\
Alcohol (excessive) & Energy intake (restricted) \\
Energy intake (excessive) & Mediterranean/varied diet \\
'Fast' food/Western-style diet & Fibre (high intake) \\
Fasting & Fish \\
Fat & Fruits/vegetables \\
Saturated fat & Garlic \\
Trans fat & Herbs and spices \\
High-fat diet & Lean game meats \\
Low $n$-3/n-6 fatty acids & Low-Gl foods \\
Fructose & Nuts \\
Glucose & Raisins \\
High glucose/Gl foods & Tea/green tea \\
Glycaemic load & Vinegar \\
Glycaemic status &
\end{tabular}

Refined carbohydrate

Salt (excessive)

Obesity/weight gain

Sleep deprivation

Smoking cessation

Smoking

Stress

('burnout')/anxiety/depression

$\mathrm{CV}$, cardiovascular; GI, glycaemic index.

* Stimuli shown on the left-hand side can cause rises in pro-inflammatory markers, often without obesity, whereas those on the right-hand side can cause an opposite reaction, or a reduction of a pro-inflammatory to neutral response (e.g. in the case of smoking cessation and weight loss) often without weight loss. See text and Egger \& Dixon ${ }^{(12)}$ for detailed references (also at www.lifestyle medicine.net.au/staging/health-information/lifestyle-medicine-evidence-base/ inflammation-database/index.htm). 


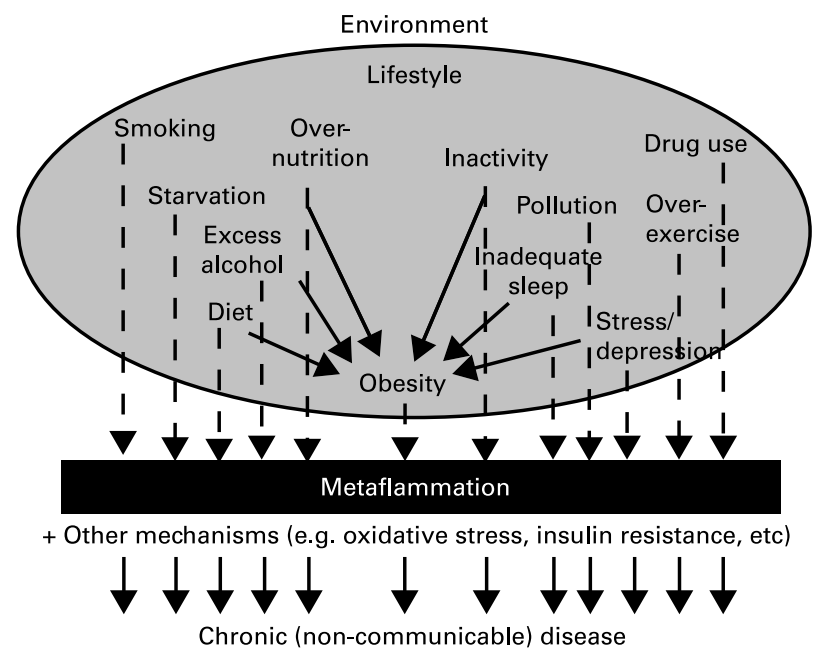

Fig. 2. Environment and lifestyle effects on the development of chronic disease through metaflammation, showing both dependent and independent effects through obesity (expanded from Wärnberg et al. ${ }^{(31)}$ ).

have been associated with physical activity and fitness ${ }^{(32)}$, a healthy lifestyle change ${ }^{(33)}$ including smoking cessation ${ }^{(34)}$, weight $\operatorname{loss}^{(35)}$ and a reduced energy intake ${ }^{(36)}$, a 'Mediterranean' style, or a varied diet ${ }^{(37)}$, and a range of nutritive factors including a moderate alcohol intake ${ }^{(15)}$, fish ${ }^{(38)}$, fruits and vegetables $^{(39)}$, herbs and spices ${ }^{(40)}$, nuts ${ }^{(41)}$, etc, all of which have been part of the human diet through long periods of evolution. (For a more detailed list of references for both pro- and anti-inflammatory inducers see Egger \& Dixon ${ }^{(12)}$ ).

All these suggest the importance of lifestyle, together with and without obesity, in the dysmetabolism often ascribed to just obesity, as many of these, and other metaflammatory inducers: (a) can have acute effects; (b) can lead to a metaflammatory reaction in the absence of obesity (e.g. smoking, sleep loss, depression); or (c) are not, in themselves, causes of obesity (e.g. smoking, environmental pollution).

\section{Factoring pro- and anti-inflammatory causes}

A significant factor distinguishing both sides of Table 1 could be labelled 'modernity', associated with the modern technoindustrial environment, arising in the main since around the time of the industrial revolution of the late nineteenth century, with inducers on the left-hand side being largely post-industrial revolution (modern), and thus relatively new to the human repertoire. Those on the right-hand side (anti-inflammatory or neutral), on the other hand, have long been part of the human evolutionary environment. On the assumption that metaflammation is triggered by an immune reaction, this would suggest that while human subjects have psychologically adopted the modern techno-industrial environment with relish, they have not yet successfully adapted to this physiologically.

The fact that these inflammatory environmental inducers and the increase in chronic diseases are linked with modernity, and, in a more distal sense, with economic growth, which is a primary driver of modernity, has been supported by recent epidemiological data, suggesting diminishing returns in aspects of health from economic growth beyond a certain point in advanced economies ${ }^{(42)}$, as well as data from 'natural' experiments such as $\mathrm{Cuba}^{(4)}$ and $\mathrm{Japan}^{(44)}$, in which major economic downturns are paradoxically associated with improvements in chronic disease rates. While not disparaging economic development (in contrast to the pure monetarily measured 'economic growth'), this supports a view, which is becoming more prevalent ${ }^{(14,42)}$, that investment in growth beyond a certain point begins to yield diminishing returns in health.

\section{Implications for health policy}

From the research evidence accumulated over the last decade, cited here and elsewhere ${ }^{(4,6,12,14)}$, it appears that metaflammation could be the link between a range of lifestyle and environmental factors (including, but not limited to, obesity), and many, if not most, modern chronic diseases. Metaflammation thus becomes to chronic disease what classical inflammation is to injury or microbial invasion, albeit with a different outcome, the latter leading usually to a resolution to homeostasis, but the former leading to dysmetabolism and chronic allostasis (see Fig. 1). Seen in this light, attempts to clinically manage obesity through diets, exercise programmes or medication are unlikely to change chronic disease rates in the community. This by no means negates the importance of weight loss in disease management, as strategies for doing this include changes to the lifestyle causes discussed here. Indeed, a range of simple lifestyle interventions can have a profound effect with the Finnish ${ }^{(45)}$, Da Quing ${ }^{(46)}$ and US Diabetes Prevention Programs ${ }^{(47)}$, all demonstrating a major reduction in the development of type 2 diabetes in those at high risk, and with greater risk reduction occurring with greater compliance to lifestyle changes, including and independent of weight loss. Recent prospective data from the Nurses Health Study have also shown independent and accumulative reductions in mortality risk over 24 years in US women with increased adherence to modified lifestyle risk factors including and independent of weight loss (not smoking, being physically active and having a healthy diet) ${ }^{(48)}$. However, a population approach to chronic disease reduction calls for something more than volitional behaviour change in one or two areas of behaviour associated with weight loss.

Obesity is a normal response to an abnormal environment ${ }^{(5)}$. Such an environment has been called obesogenic ${ }^{(5)}$, and, more recently, inflammatory ${ }^{(14)}$, metaphorically linking obesity with climate change. Increased levels of obesity in the community in this light can be seen as '... the unintended but unavoidable consequences of economic progress ${ }^{\text {,49) }}$, presenting as an accomplice, as much as a perpetrator, in many, if not all, of the chronic diseases associated with that modernity.

The hypothesis proposed here - that human subjects have an induced inflammatory reaction to the modern techno-industrial environment to which they have not evolved or adequately adapted - poses some interesting questions and provides challenging dilemmas and possible solutions in relation to this.

First, how can the distal determinants of such a response (e.g. industrialisation/the modern Western environment/ economic growth) be managed without abandoning the obvious human advantages they have brought to date? There is little doubt that, to a point at least ${ }^{(42)}$, economic growth has been 
the single biggest driving force behind improved health and well-being since the start of the industrial revolution ${ }^{(50)}$. The world economic crisis beginning in 2007-8 has signalled to many, however, not just a need for a reordering of the current system, but for a paradigm shift in the growth system of economics ${ }^{(51,52)}$, thus echoing the views of its early architects such as Mill ${ }^{(53)}$ and Keynes ${ }^{(54)}$ that growth would need to be pursued for a time, but eventually would need to be replaced by an alternative system that focused more on human improvement ${ }^{(53)}$ (presumably including health). This is because, as recognised then, but often overlooked in the current growth-dominated political environment, nothing can grow forever. As stated by one observer: '.. after maturity, continued growth is either obesity or cancer'(55). This also signals the need for health scientists to become involved in the economic debate.

Second, what is the connection between obesity and chronic disease in the absence of damaging lifestyle cofactors? Does the fit-but-fat phenomenon reduce the need for a population emphasis on weight control in favour of an increased emphasis on other aspects of lifestyle (such as activity levels, sleep, stress management, etc) and the inflammatory environment, with possible beneficial impact on both the biological and ecological environments ${ }^{(14)}$ ? Health and environmental issues, such as pollution and climate change, have recently been shown to be intimately associated through the use of non-renewable fossil fuels in transport, also leading to reduced personal energy expenditure and increased obesity ${ }^{(14,56)}$.

Finally, what can be done to counteract this environmentinitiated epidemic, given that a return to a pre-industrial society is unlikely? It is not the intention here to detail what will obviously be a complex and multidisciplinary response, which is often considered outside the realm of health scientists, but which we propose is integral to the management of chronic disease. There is a need for an array of workable solutions at many levels of modern society, and away from an isolated view of health and obesity as simply a pharmaceutical problem. While a major economic paradigm shift such as that suggested previously is unlikely to happen in the immediate future, interim initiatives such as corporate and personal carbon trading have begun to be put in place to moderate the effects of unlimited growth, albeit serendipitously through rising interest in climate change ${ }^{(14,56)}$, but also with a potential benefit in managing the chronic disease epidemic ${ }^{(12,14,57)}$. There are still many answers to be provided, however, and undoubtedly many more questions arising from these suggestions, for which health scientists will need to expand their horizons.

\section{Acknowledgements}

The authors acknowledge no conflicts of interest or funding for the present paper. G. E. acted as the main author and J. D. contributed as the joint author to the final copy.

\section{References}

1. Hotamisligil GS, Shargill NS \& Piegelman BM (1993) Adipose expression of tumor necrosis factor-alpha: direct role in obesity-linked insulin resistance. Science 259, 87-91.
2. Hotamisligil GS (2006) Inflammation and metabolic disease. Nature 444, 860-867.

3. Libby P (2007) Inflammatory mechanisms: the molecular basis of inflammation and disease. Nutr Rev 65, S140-S146.

4. Mantovani A, Allovena P, Sica A, et al. (2008) Cancer related inflammation. Nature 454, 436-444.

5. Egger G \& Swinburn B (1996) An ecological model for understanding the obesity pandemic. Br Med $J \mathbf{2 0}$, 227-231.

6. Medzhitov R (2008) Origin and physiological roles of inflammation. Nature 454, 428-435.

7. Hajer GR, van Haeften TW \& Visseren FLJ (2008) Adipose tissue dysfunction in obesity, diabetes, and vascular diseases. Eur Heart J 29, 2959-2971.

8. Frayn KN (2002) Adipose tissue as a buffer for daily lipid flux. Diabetologia 45, 1201-1210.

9. Wajchenberg BL (2000) Subcutaneous and visceral adipose tissue: their relation to the metabolic syndrome. Endocr Rev 21, 697-708

10. Karelis AD, St-Pierre DH, Conus F, et al. (2004) Metabolic and body composition factors in subgroups of obesity: what do we know? J Clin Endocrinol Metab 89, 2569-2575.

11. Wildman RP, Muntner P, Reynolds K, et al. (2008) The obese without cardiometabolic risk factor clustering and the normal weight with cardiometabolic risk factor clustering: prevalence and correlates of 2 phenotypes among the US population (NHANES 1999-2004). Arch Intern Med 168, $1617-1624$.

12. Egger G \& Dixon J (2009) Should obesity be the main game? Or do we need an environmental makeover to combat the inflammatory and chronic disease epidemics? Obes Rev 10, $237-249$

13. O'Keefe JH, Gheewala NM \& O'Keefe JO (2008) Dietary strategies for improving post-prandial glucose, lipids, inflammation, and cardiovascular health. $J$ Am Coll Cardiol 51, 249-255.

14. Egger G (2008) Dousing our inflammatory environment(s): is personal carbon trading an option for reducing obesity - and climate change? Obes Rev 9, 456-463.

15. O'Keefe JH, Bybee KA \& Lavie CJ (2007) Alcohol and cardiovascular health: the razor-sharp double-edged sword. J Am Coll Cardiol 50, 1009-1014.

16. Solinas G, Vilcu C, Neels JG, et al. (2007) JNK1 in hematopoietically derived cells contributes to diet-induced inflammation and insulin resistance without affecting obesity. Cell Metab 6, 386-397.

17. Esmaillzadeh A, Kimiagar M, Mehrabi Y, et al. (2007) Dietary patterns and markers of systemic inflammation among Iranian women. $J$ Nutr 137, 992-998.

18. Håversen L, Danielsson KN, Fogelstrand L, et al. (2009) Induction of proinflammatory cytokines by long-chain saturated fatty acids in human macrophages. Atherosclerosis 202, 382-393.

19. Harvey KA, Arnold T, Rasool T, et al. (2008) Trans-fatty acids induce pro-inflammatory responses and endothelial cell dysfunction. Br J Nutr 99, 723-731.

20. Rayssiguier Y, Gueux E, Nowacki W, et al. (2006) High fructose consumption combined with low dietary magnesium intake may increase the incidence of the metabolic syndrome by inducing inflammation. Magnes Res 19, 237-243.

21. Dickinson S, Hancock DP, Petocz P, et al. (2008) Highglycemic index carbohydrate increases nuclear factor-kappaB activation in mononuclear cells of young, lean healthy subjects. Am J Clin Nutr 87, 1188-1193.

22. Simpson N \& Dinges DF (2007) Sleep and inflammation. Nutr Rev 65, S244-S252. 
23. Thorley AJ \& Tetley TD (2007) Pulmonary epithelium, cigarette smoke, and chronic obstructive pulmonary disease. Int J Chron Obstruct Pulmon Dis 2, 409-428.

24. Kulmatycki KM \& Jamali F (2006) Drug disease interactions: role of inflammatory mediators in depression and variability in antidepressant drug response. J Pharm Pharm Sci 9, 292-306.

25. Hickling S, Hung J, Knuiman M, et al. (2008) Are the associations between diet and C-reactive protein independent of obesity? Prev Med 47, 71-76.

26. Watt MJ (2009) Storing up trouble: does accumulation of intramyocellular triglyceride protect skeletal muscle from insulin resistance? Clin Exp Pharmacol Physiol 36, 5-11.

27. Galgani J, Aguirre C \& Diaz E (2006) Acute effect of meal glycaemic index and glycaemic load on blood glucose and insulin responses in humans. Nutr $J \mathbf{5}, 22-28$.

28. van der Crabben SN, Allick G, Ackermans MT, et al. (2008) Prolonged fasting induces peripheral insulin resistance, which is not ameliorated by high-dose salicylate. J Clin Endocrinol Metab 93, 638-641.

29. Hamburg NM, McMackin CJ, Huang AL, et al. (2007) Physical inactivity rapidly induces insulin resistance and microvascular dysfunction in healthy volunteers. Arterioscler Thromb Vasc Biol 27, 2650-2656.

30. Neubauer O, König D \& Wagner KH (2008) Recovery after an Ironman triathlon: sustained inflammatory responses and muscular stress. Eur J Appl Physiol 104, 417-426.

31. Wärnberg J, Nova E, Romeo J, et al. (2007) Lifestyle-related determinants of inflammation in adolescence. Br J Nutr 98, Suppl. 1, S116-S120.

32. Brooks SV, Vasilaki A \& Larkin LM (2008) Repeated bouts of aerobic exercise lead to reductions in skeletal muscle free radical generation and nuclear factor kappaB activation. J Physiol 586, 3979-3990.

33. Balagopal P, Graham TE, Kahn BB, et al. (2007) Reduction of elevated serum retinol binding protein in obese children by lifestyle intervention: association with subclinical inflammation. J Clin Endocrinol Metab 92, 1971-1974.

34. Lao XQ, Jiang CQ, Zhang WS, et al. (2009) Smoking, smoking cessation and inflammatory markers in older Chinese men: The Guangzhou Biobank Cohort Study. Atherosclerosis 203, 304-310.

35. You $\mathrm{T} \&$ Nicklas BJ (2006) Chronic inflammation: role of adipose tissue and modulation by weight loss. Curr Diabetes Rev 2, 29-37.

36. Jolly CA (2004) Dietary restriction and immune function. $J$ Nutr 134, 1853-1856.

37. Bulló M, Casas-Agustench P, Amigó-Correig P, et al. (2007) Inflammation, obesity and comorbidities: the role of diet. Public Health Nutr 10, 1164-1172.

38. Nakamura Y, Ueno Y, Tamaki S, et al. (2007) Fish consumption and early atherosclerosis in middle-aged men. Metabolism 56, $1060-1064$.
39. Wannamethee SG, Lowe GD, Rumley A, et al. (2006) Associations of vitamin $\mathrm{C}$ status, fruit and vegetable intakes, and markers of inflammation and hemostasis. Am J Clin Nutr 83, 567-574.

40. Tapsell LC, Hemphill I, Cobiac L, et al. (2006) Health benefits of herbs and spices: the past, the present, the future. Med J Aust 185, 4 Suppl., S4-S24.

41. Kris-Etherton P, Hu FB, Ros E, et al. (2008) The role of tree nuts and peanuts in the prevention of coronary heart disease: multiple potential mechanisms. J Nutr 138, 1746S-1751S.

42. Tapia Granados JA \& Ionides EL (2008) The reversal of the relation between economic growth and health progress: Sweden in the 19th and 20th centuries. J Health Econ 27, 544-563.

43. Franco M, Orduñez P, Caballero B, et al. (2007) Impact of energy intake, physical activity and population-wide weight loss on cardiovascular disease and diabetes mortality in Cuba, 1980-2005. Am J Epidemiol 166, 1374-1380.

44. Tapia Granados JA (2008) Macroeconomic fluctuations and mortality in postwar Japan. Demography 45, 323-343.

45. Herder C, Peltonen M, Koenig W, et al. (2006) Systemic immune mediators and lifestyle changes in the prevention of type 2 diabetes: results from the Finnish diabetes prevention study. Diabetes 55, 2340-2346.

46. Li G, Zhang P, Wang J, et al. (2008) The long-term effect of lifestyle interventions to prevent diabetes in the China Da Qing Diabetes Prevention Study: a 20-year follow-up study. Lancet 371, 1783-1789.

47. Haffner S, Temprosa M, Crandall J, et al. (2005) Intensive lifestyle intervention or metformin on inflammation and coagulation in participants with impaired glucose tolerance. Diabetes 54, 1566-1572.

48. van Dam RM, Li T, Spiegelman D, et al. (2008) Combined impact of lifestyle factors on mortality: prospective cohort study in US women. BMJ 337, a1440.

49. Roberts P (2008) The End of Food: The Coming Crisis in the World Food Industry. London: Bloomsbury.

50. Riley JC (2001) Rising Life Expectancy: A Global History. New York: Cambridge University Press.

51. Daly HE (1996) Beyond Growth. Boston, MA: Beacon Press.

52. Meadows DH, Randers J \& Meadows DL (2004) Limits to Growth: The 30-Year Update. White River Junction, VT: Chelsea Green Publishing.

53. Mill JS (2003) Principles of Political Economy, 1848. Electronic reproduction. Palo Alto, CA: e-brary.

54. Keynes JM (1936) The General Theory of Employment, Interest and Money. New York: Harcourt Brace and World.

55. Bartlett AA (2008) What part of arithmetic does not hold in Boulder? Boulder Daily Camera, February 3, p. 10.

56. Faergeman O (2007) Climate change and preventive medicine. Eur J Cardiovasc Prev Rehabil 14, 726-729.

57. Egger G (2007) Personal carbon trading: a potential 'stealth intervention' for obesity reduction? Med J Aust 187, 185-187. 